\title{
Mágica fecha de Manuel Andújar, el fino hilo de unión entre distopía y realismo
}

\author{
Recibido: 25/10/2017
}

Aceptado: 19/12/2017

\section{RESUMEN:}

En el ciclo narrativo Lares y penares Manuel Andújar trató de explicar la naturaleza de la España contemporánea recurriendo a la historia reciente. La novela que le da fin, Mágica fecha, se sitúa en el futuro y no es una obra realista ni testimonial. En este artículo se tratará de explicar por medio de un análisis genérico cómo habla la distopía del contexto socio-politico del autor andaluz, y por lo tanto de qué manera se inserta en el ciclo citado.

PALABRAS CLAVE: Manuel Andújar, Mágica fecha, distopía, testimonio.

Mágica fecha by Manuel Andújar, the weak bond between dystopia and realism

\begin{abstract}
:
In his narrative cycle Lares y penares Manuel Andújar tried to explain the nature of contemporary Spain by looking into its recent History. The last novel of the cycle, Mágica fecha, takes place on a future tempus and, therefore, it is not a realistic nor testimonial literature. This paper aims to explain through a generic approach how does the dystopia speak about the sociopolitical context of the Andalusian autor and thus how it fits in the aforementioned cycle.
\end{abstract}

KEY WORDS: Manuel Andújar, Mágica fecha, dystopia, testimony. 


\section{Lares y penares: realismo simbólico}

Las narraciones de Manuel Andújar constan de un poso histórico considerable, que ha llevado a muchos autores a describirlas como narraciones realistas o testimoniales. El ciclo Lares y penares, compuesto entre 1947 y 1989, aglutina la mayor parte de las novelas del autor, todas escritas con un principio común: la necesidad de explicar el fenómeno de la Guerra Civil a través de los personajes «anónimos» de la Historia (Alarcón Sierra, 2015: 146).

Pero definir la producción narrativa de Andújar como realista es dar una visión parcial de la misma. Dentro del mismo ciclo Lares y penares se puede establecer una distinción entre un primer «realismo ético» (Conte, 1981: 548-549) y un estilo posterior, «enigmático y onírico [...], más denso, más barroco, menos funcional y naturalista», «simbólico», en el que «la alegoría ocupa un lugar mayor» (Martínez Aguilar, 1989: 116). Este cambio de estilo lo describían ya los contemporáneos al autor, como Aguilera Malta cuando, en 1962 (8), anotaba: «Él [Manuel Andújar], que siempre plasmaba sus creaciones con elementos realistas $[\ldots]$, hoy está espigando nuevos derroteros, nuevas fórmulas, nuevos métodos estéticos e, inclusive, nuevos géneros [el teatro]».

Pero ambas técnicas narrativas pertenecen a una intención continuada. Alarcón Sierra (2015: 144) habla del estilo para él invariable del autor como un «realismo simbólico» consistente en la profunda preocupación por alcanzar el sentido último de los sucesos narrados, un intento constante por plasmar la «interpretación de los hechos a través de una visión perspectivística, polifónica y dialógica», y Santos Villanueva es partícipe de esta opinión:

De ninguna manera Andújar deja de ser el escritor hondamente realista de siempre, sino que amplía los mecanismos de observación mediante la intensificación de lo ensoñado y lo intuido. Un 
realismo moral, un realismo de conciencias por el que discurren los fantasmas de nuestro tiempo va sustituyendo al realismo testifical. [...] La vida española finisecular, con tantos cambios en su sistema de valores tradicionales y con muchos episodios de picaresca mayor y menor, necesita un tratamiento artístico que desvele lo que oculta una realidad con frecuencia esperpéntica (1995: XX).

En el contexto de esa producción matizadamente «realista»y cerrando el ciclo Lares y penares encontramos Mágica fecha, novela poco estudiada por la crítica ${ }^{1}$ que se ambienta en un contexto futuro, desligándose $-\mathrm{O}$ al menos eso parece- del devenir histórico. Escrita entre 1970 y 1974, años en los que el autor se enfrentaba a la censura para la publicación de Historias de una historia (1973) y Los lugares vacíos (1971), obras finalmente «mutiladas» por la misma (Andújar, 1987: 21; Medina Ávila, 2014: 413416; Beneyto, 1975: 86), la novela fue retocada a principios de los años 80 (Andújar apud Medina Ávila, 2015: 1408) y publicada en la editorial Anthropos en $1989^{2}$.

Presentar una novela ambientada en el futuro como una obra integrada en un ciclo «realista simbólico», con raíces en la historia real y con un interés específico por el devenir de la España contemporánea exige una justificación. Eso es lo que se tratará de proporcionar en este artículo, a partir de un análisis genérico de Mágica fecha y de un intento de explicación de la forma en que la ficción distópica interactúa con la realidad del lector.

1 Hasta el momento el aparato crítico acerca de esta obra se concentra en las reseñas de Ángel Basanta (1990) y Rafael Conte (1990) y en contados comentarios entreverados en análisis de conjunto, que aluden siempre a su complejidad estructural.

2 Citaremos la obra siempre por esta edición, en adelante MF. Existe una reedición de la obra en 2004 de la editorial SIC idea y creación editorial en la colección Biblioteca de autores andaluces, aunque con algunos cambios en la disposición tipográfica de determinados pasajes, en la primera edición presentados a dos columnas. 


\section{Mágica fecha, obra distópica}

A la hora de definir Mágica fecha, la crítica se ha valido de distintas etiquetas genéricas: Santos Villanueva (1995: XXI) habla de ciencia ficción, Alarcón Sierra (2015: 157) la describe como una «fábula moral, distopía futurista y alegórica» y Hervás Fernández (2011: 167) dice de ella que su «trama narrativa recuerda vagamente aquella otra de Huxley en Un mundo feliz», comparativa que Medina Ávila (2015: 441) extiende a Farenheit 451 y a 1984, y que Antón Castro (apud Medina Ávila, 2014: 440) ratifica, emparentando al autor con George Orwell, Arthur Koestler y Víctor Serge. Que Andújar conociese la producción de alguno de estos autores no sería raro, teniendo en cuenta su empleo en editoriales, y en el caso de Aldous Huxley —que colaboró en la revista Las Españas, codirigida por el intelectual andaluz (Abellán, 1994: 289) - parece innegable. Pero, además, el propio autor se ha pronunciado al respecto de la tipología genérica a la que pertenece su creación: en una nota adjunta al manuscrito que envía a Carmen Balcells en 1974, Andújar afirma de Mágica fecha que «no es ciencia ficción, sino [su] visión premonitoria de lo que será entonces la vida humana, española, desde las actuales premisas, en ese futuro subyacentes» (Andújar apud Medina Ávila, 2014: 439). Todas estas afirmaciones nos permiten estudiar Mágica fecha a partir del canon del género distópico.

Bien es cierto que existen ciertos inconvenientes para dicho estudio, como son la indeterminación terminológica que afecta a la nomenclatura del género distópico - junto a distopía conviven etiquetas como anti-utopía, utopía invertida, utopía negativa, utopía regresiva, cacotopía, no-utopía, utopía satírica (Galán Rodríguez, 2007:116) - y la tendencia a definirlo ad contrarium, como mero descendiente histórico de la utopía (Calatrava, 2010: [s. p.]; Stringer, 1994: 686; Cuddon, 1999: 959; Gray, 2004: 299; Shipley, 1962: 532; Van Gorp et al., 2001: 495). Eludiendo estas cuestiones -indicativas de la necesidad de un estudio más profundo del género- en el presente artículo procederemos al análisis de la obra valiéndonos de ciertas características identificables en la 
mayor parte de los textos pertenecientes al canon distópico, que cualquier lector podría extraer inductivamente de sus lecturas.

Podemos empezar por el contexto en que se ambienta la narración: la distopía se construye en un mundo mimético ficcional verosímil (Albaladejo apud Rodríguez Pequeño, 1995: 134-137), que transgrede las reglas del mundo real, pero es percibido por el lector como creíble. Su verosimilitud se justifica generalmente por la lejanía espacio-temporal que mantiene con respecto al mundo real: con un distanciamiento del contexto temporal en el que escribe el autor, la distopía tiende a situarse en el planeta Tierra. Suele darse además que la acción cotidiana o personal de los protagonistas transcurre en ambientes urbanos, artificiales y geométricos, espacios asignados a «la raza humana en contraposición al mundo animal» (Saldías Rossel, 2015: 148), civilizados y no bárbaros. En el espacio urbano cobra especial importancia la descripción de los edificios, entre los cuales a menudo se incluyen grandes fábricas y aparatos mecánicos e industriales, o avances técnicos que se perciben en el transcurso de la vida urbana.

Esto es lo que ocurre en Mágica fecha, situada en el Madrid del último día de 1999: un contexto conocido por los lectores, que toma del actual los nombres de sus calles y edificios, pero alterado por el paso del tiempo. Algo que no existe aún pero que es susceptible de existir ${ }^{3}$. La sociedad futura se entiende como un desarrollo inevitable del presente del autor, «época bárbara, tan pretérita e imperfecta» (MF: 104), aunque no se explicite cómo

3 Podría argumentarse que la aplicación del adjetivo verosímil a esta obra plantea un inconveniente. Nemesio, uno de los ayudantes del Doctor Milenio, afirma tener comunicación con dos fantasmas, el del camarero Macareno y el del taxista Felipe, que pronostican la muerte de Jerónimo. No obstante, la interpretación de si estas voces del más allá realmente existen o no quedará abierta: ese don es para el Doctor «una codificada y consustancial sapiencia» (1989: 190), pero también «carente de rigor» e «impugnable» (MF: 285), y el resto de subordinados del médico lo consideran «supersticiones y delirios» (MF: 197). Así, podemos aseverar que el mundo ficcional en que tiene lugar la obra es verosímil, pues la existencia de personajes más o menos crédulos, más o menos fantasiosos no pone en peligro la credibilidad del constructo coordinado de espacios, tiempos y sucesos en los que se inscriben. 
se ha dado tal evolución. Se pueden ir recogiendo algunos datos del texto, especialmente en las numerosas analepsis introducidas por los personajes, y así es posible saber que en algún momento del pasado se consiguió «sortear la catástrofe total», innominada; que el Arcaico estuvo en un campo de concentración, que fue encarcelado y que se le conmutó la pena... e incluso que hubo un episodio bélico en 1939: la Guerra Civil («igual a un soldado que salta una trinchera alambrada -1939—» (MF: 194)); estos datos permiten la rápida asociación de ambas etapas, la presente y la futura, por medio del reconocimiento de un pasado histórico común.

En la descripción de ese locus urbano en el que transcurre la acción se plasma también el paso del tiempo a la vez que se establece un vínculo entre el presente y el pasado. Es un Madrid renovado, reconocible solo por su alterada topografía: el Científico Cimero evoca «el hangar del aeropuerto, elevado en plataforma, del Manzanares», y el «complejo típico reconstruido en torno a la ermita de San Antonio de la Florida» (MF: 50). La ciudad se presenta como una masa enorme y ordenada, descrita por Jerónimo como «interminables territorios de bloques urbanos, lejanas montañas, horizontes por entero surcados del cablerío y verrugas de almacenes, parejas techumbres de fábricas, cristaleros chalets-laboratorios» (MF: 185). Es la ciudad moderna, industrializada, en la que se acusa la pérdida de la existencia orgánica y de la armonía del hombre con el medio natural. Es el paisaje mutilado, reducido a su capacidad productiva, consumible o investigable, que coarta la expansión individual del ser humano y su realización como individuo perteneciente a una comunidad (MF: 187).

En la obra de Andújar prevalecen, eso sí, lugares alternativos, que por contraste resaltan el urbanismo desaforado de Madrid. Uno de esos espacios es la Miniciudad Amurallada, «máximo muestrario arquitectónico nacional» construido sobre el actual parque natural de la «Dehesa de la Villa» (MF: 84). En su abigarramiento encontramos los «fragmentos de los más indicativos 
estilos arquitectónicos y por ende [...] eslabones de nuestra marcha histórica, [que componen] la unidad orgánica en que el alma patria ha de oxigenarse y crecer» (MF: 85). Edificada y cuidada mediante técnicas de construcción arcaicas, la Miniciudad es un museo del pasado que se opone a la urbe habitable. Es cierto que, como museo, su orden no queda muy claro, aunque se presume una función histórica — en cada lugar, «hombres-historia» atienden «con autenticidad léxica e indumentaria» a los visitantes (MF: 85)—: se encuentran juntos el Museo del Prado, la Plaza Mayor y el Manzanares contiguos al barrio gótico de Barcelona y a las juderías de Sevilla y Córdoba; al lado de los edificios nacionales está el Barrio Internacional de la Miniciudad Amurallada, en que se han reconstruido la Universidad de Heidelberg, el minarete de la Meca, el palacio de Gorkigrado o la Corte de Versalles, por ejemplo.

Y al margen de la civilización persisten aún vacíos, como aquel solar en que se refugian el científico Cimero y Matilde, pendientes de urbanización. Este terreno, conocido como «La Cochambre», es descrito como un locus amoenus abocado a la extinción (MF: 47). En este oasis solitario el hombre es capaz de la reflexión introspectiva $y$, en sus encuentros con otros individuos, puede proceder a la relación, al conocimiento profundo de sentimientos y sucesos pasados: es lo que se ve en la interacción de Cayetano Heriberto con Matilde. El espacio de incivilización permite al hombre conocerse y sentirse en plenitud —como también ocurriese en el cuento de Andújar «La ilusión subversiva» (1989)—.

Subyace, en ese contexto futuro, cierto cientificismo. Encontramos en él elementos típicos de la ciencia ficción, que muchas veces se entienden como avances experimentales de la ciencia presente, logrados con el paso del tiempo. La asociación de ciencia y «avance» $\mathrm{o}$ «desarrollo», propia de la modernidad en la civilización occidental, provoca una reacción común de los autores distópicos, que a menudo muestran los peligros de la evolución científica, la forma en que los avances científico-técnicos pueden perjudicar al hombre. 
En Mágica fecha nos encontramos con instrumentos como la lente radial que el Científico Cimero utiliza para aniquilar a los animales que pueblan la cueva en que se esconde en La Cochambre (MF: 47), o incluso la exuberante productividad de la urbe, que plantean las consecuencias de la evolución técnica; ya desde el comienzo de la novela la relación entre el hombre y la tecnología se pone en cuestión: la aversión que le produce a Tiburcio la «caña de pescar»y su deseo de que el «bicho» falle en el desarrollo de su tarea (MF: 9-10), o los maniquíes mecánicos, a los que el empleado llama «intrusos, mamarrachos, suplantadores, "racionalistas"» (MF: 13) y que se asemejan a una masa humana - la comparación, profundamente simbólica, es ineludible- en la que se ha perdido la individualidad, son ejemplos de la tensión existente entre el hombre y las máquinas con las que convive, a las que prácticamente necesita para llevar a cabo su función existencial. No faltan, sin embargo, voces que reniegan de su uso, como la de los «longevos» Calixto y Lucrecia, que prefieren ser «bípedos» subiendo escalón tras escalón a utilizar las «escaleras rodantes» de su vivienda, reclamando el ejercicio físico en su pequeño acto subversivo $(\mathrm{MF}, \S$ «El pozo de la escalera»: 29-33); o como el igualmente «longevo» (y pueblerino) Zacarías, que prefiere pasear hasta la casa de su hija en lugar de sobrevolar la ciudad.

La ciencia médica y sanitaria también se ha desarrollado, dando lugar a avances como la cirugía «estético-geriátrica» (MF: 17), la alimentación sintética o la detención del envejecimiento de Jerónimo, el inmortal, varado en la edad que tenía en 1960 (MF: 104). Y la ambición desarrollista no se detiene en estas invenciones, sino que se aspira incluso a controlar la muerte hasta el punto de lograr la resurrección humana (MF: 17).

Para el desempeño de la investigación científico-tecnológica existen distintas instituciones, como la Academia Científica y el Centro Impulsor de Programación Futurológica, que se rigen por una lógica extrema y rechazan la importancia de la imaginación para cualquier tipo de investigación o desarrollo. La Academia 
Científica, en el coloquio presidido por el Científico Cimero, se plantea la posibilidad de «industrializar [...] los privativos y acumulados mitos hispánicos», mediante campos de estudio como la «bacteriología sofística» y la «fisiognomía del empecinamiento» (MF: 52): la tecnología, «al servicio de la Humanidad» (MF: 52), desdeña el estudio del hombre, la indagación filosófica, la continua duda, y piensa que la finalidad de la «cualidad pensante» tiene que ser algún tipo de producto capitalizable (MF: 53). La misma forma de pensar tienen los futurólogos, para quienes «no se construye el porvenir, que es nuestro movedizo terreno, con abstracciones. O especulaciones» (MF: 152), y que no entienden el provecho que puede residir en la «facultad puramente imaginativa, fecundamente fantaseadora» (MF: 152).

En ese contexto cercano en lo espacial pero temporalmente distante y regido por el desarrollo tecnológico, un conjunto de seres humanos convive en una estructura política y social. El Estado sujeta a sus ciudadanos a un férreo control mediante una estricta legislación y una organización funcionarial y burocrática fuertemente institucionalizada, en la que cada miembro de la sociedad supedita sus intereses al mantenimiento del statu quo: en ese sistema todos son útiles pero prescindibles, se «pone siempre el todo por encima de las partes» (Ímaz, 1941: 27). Se percibe así la sociedad como una enorme máquina de la que el individuo es a la vez trabajador y producto, a la que sirve y sin la que no podría sobrevivir. Y esta ordenación social impera por encima de los organismos tradicionales de vida en comunidad como la familia o la pareja.

Los últimos mandatarios de ese sistema burocrático de estructura piramidal en la novela tratada son quizás los llamados «Poderes de la organización Intangible» (MF: 284), bajo los cuales, en un organigrama desconocido para el lector, se agrupan el Jefe de Estado, Gran Autoridad Primeriza, los Benéficos Magistrados, Emisarios de los Eficientes Magistrados, Delegados, Oficiales-Jefe, el Colegio de Relatores, las Compañías Recreativas Discrecionales, etc. Por debajo están el resto de ocupaciones 
laborales, «socialmente asignadas» (MF: 81) por un «catalogador, o catador, del combinado vocacional» (MF: 60), que olfatea las cualidades de los individuos para decidir en qué puesto serán de mayor utilidad para la comunidad. Este sistema no se traduce necesariamente en la conformidad de los trabajadores: Cristóbal y Dionisio, «mozos de cuerda», se sienten «condenado[s] a un oficio monótono, inferior, desde niño[s]» (MF: 81). Es cierto que, gracias a la función del Alto Comisario de las Condecoraciones, encargado de distribuir los «honores simbólicos», la mayor parte de los ciudadanos es feliz, por lo que la sociedad española ha logrado el auge productivo que la sitúa «a la cabeza del mundo cultural representativo» (MF: 207); pero, de nuevo, las condecoraciones y el reconocimiento de los méritos no es suficiente para todos, y los mismos Dionisio y Cristóbal, a quienes poca gente «aventaja en medallas pensionadas del mérito laboral» (MF: 81$)$ no reciben satisfacción de sus muchos premios. Hay quienes, como el Científico Cimero, son conscientes de que condecoraciones y actos son un mecanismo estatal de control - a él «todavía le atormentaba aquella revulsión, que, "científicamente", le provocaba el artificio y la puerilidad convencional del acto en que habían proclamado su excepcional mérito y correspondiente celebridad» (MF: 50)—.

Por otro lado, el aparato estatal está de algún modo legitimado por un alto fin, revestido de valores como la felicidad, la justicia o la igualdad, de modo que aparece como un sistema de vida consensuado por sus integrantes, que lo aceptan y en ocasiones incluso lo veneran. La represión del Estado es la herramienta mediante la que se reconduce a aquellos individuos que, por alguna alteración aparentemente ilógica de la conducta, se ven impelidos a contravenir las normas aceptadas, poniendo en peligro el bienestar de la comunidad.

Es una medida alienante que subordina todos los aspectos de la vida del individuo al óptimo desarrollo de la colectividad, elemento propio del género distópico. Como las mujeres de Dionisio y Cristóbal, esos hombres desencantados con sus trabajos, se encargan de recordar: 
- La Constitución está fundamentada en certeras normas de eficacia. Se trata de aprovechar al máximo las capacidades personales, de evitar los despilfarros y desórdenes que acarreaban un sinfín de caprichitos y los usos viciados de la determinación. (MF: 81)

La meta de la «eficacia» alcanza todos los niveles de la existencia de los madrileños. El orden de la misma ciudad está fuertemente estipulado, y los individuos viven en distintos «distritos de habitabilidad» a los que se otorgan privilegios dispares (MF: 15), quizás en función del estatus social de sus integrantes (aunque no se especifica en el texto). Por otro lado, el «padrón domiciliario» es «vitalicio e inmodificable», pues se considera que «la vieja mudanza es lujo y puerilidad» (MF: 56), un capricho sin ninguna función ni meta social.

Y como conformantes de dicha sociedad están los ciudadanos, seres humanos alienados de algún modo, cuya existencia tiene la importancia única de funcionar como engranaje en el gran mecanismo comunal. La deshumanización es la forma más común en la que los autores distópicos muestran la impotencia de los habitantes de los Estados anti-utópicos: cosificados o brutalizados, convertidos en máquinas lógicas o en animales instintivos, no constituyen hombres completos.

La eugenesia, la educación, el racionalismo más exagerado, la manipulación química, la cirugía cerebral o la manipulación lingüística — siguiendo la hipótesis de Sapir-Whorf, que, a grandes rasgos, postula la existencia de una relación entre el lenguaje de un individuo y la manera en que este conceptualiza el mundo que le rodea (Galán Rodríguez, 2007: 120)— son medios de los cuales se vale el Estado para dominar la voluntad del individuo. Los hombres son reinventados, creados para adaptarse de la mejor forma posible a su función dentro de la sociedad distópica; para ello será conveniente que carezcan de libre albedrío, que no puedan ejercer su propia voluntad. En la mayor parte de los casos, los habitantes de estas comunidades no son conscientes de esta circunstancia, y además no tienen capacidad de relación con 
el resto de individuos, por lo cual es improbable que alcancen el conocimiento de su propia situación.

En Mágica fecha el control supera los límites del funcionariado y se extiende a todas las relaciones humanas. Los matrimonios también están regulados: Úrsulos y Reginos no sólo sufren como una imposición sus empleos; su emparejamiento, cuya finalidad es eugenésica, es producto del plan estatal:

La Ley disponía que los vigorosos natos, clasificados, únicamente podían contraer matrimonio con expertas en computadores. Se aliaban, de acuerdo con la inspiración magnánima de las ordenanzas, los elementos genéticos que al ayuntarse aportaría hijos de armónica ambivalencia, los más adecuados que en funciones mixtas ha de requerir el Estado tras rigurosa evolución y probable diversificación secundaria. (MF: 82)

Sin embargo, la ley no contempla fallos como la infecundidad, que invalidarían la «funcionalidad» que reviste el control estatal causando la infelicidad del individuo. Este aspecto indica la existencia de fallas en el principio regente del orden del Madrid de diciembre de 1999.

Con finalidad eugenésica existen además «Reales Ordenanzas de instrucción e higienes [sic] matrimoniales» (MF: 63), que anualmente seleccionan por sorteo a qué niñas se les «extirpará» la capacidad de concebir (MF: 64) para evitar la sobrepoblación. Esta práctica no está desprovista de consecuencias en la salud de las mujeres castradas, que como «madrecita» desarrollan enfermedades mortales a causa de la «mutilación» (MF: 67).

La educación también está fuertemente planificada. Aunque no es un tema recurrente en Mágica fecha, sí se menciona la existencia de un «básico adiestramiento ciudadano», que comienza a la edad de seis o siete años, y de un «plan de enseñanza familiar bajo severo control colectivo» (MF: 14). El cuidado de la infancia 
excluye la narración de cuentos e historias (MF: 18), y acarrea una atención alimenticia extremadamente minuciosa (MF: 179).

E incluso la muerte está sujeta a imposiciones. No se permite a los individuos morir sin más, sino que se intenta alargar su vida hasta el momento inevitable. Con el fin de alcanzar el mayor provecho para el avance científico, todo hombre es sujeto de examen en sus momentos finales, y ha de padecer sus enfermedades siendo objeto de estudio en un hospital. La huida de Matilde con «madrecita», para que esta muera «como sujeto, en ejercicio de albedrío» (MF: 68), es un «crimen social» (MF: 59), como también lo es el suicidio del Científico Cimero.

Los mecanismos de control de la ciudadanía afectan tanto al ámbito público como al privado. Para vigilar la correcta aplicación de las leyes, el Estado cuenta con una serie de mecanismos de vigilancia, más o menos invasivos, en constante funcionamiento. El Científico Cimero está sujeto al exhaustivo estudio químico: se vigilan su conducta sexual, sus desechos y todos los aspectos de su vida, que de algún modo indican su peligrosidad (MF: 51). Existe, de hecho, un «Tabular Registro Íntimo» (MF: 209) en el que está recogido el pasado de todos los habitantes del Estado (salvo contadas excepciones). Pero además, Jerónimo, desde su reclusión panóptica - «la torre semejaba un faro de estructura transparente, monumento de mecánicas pupilas avizores, mirar fijo y captador» (MF: 103)—, puede captar el «ánimo civil», accediendo a los sentimientos y recuerdos de los ciudadanos, a los que ve reflejados en una pantalla. Es el espía encargado de indicar la «peligrosidad social» (MF: 110) de sus compatriotas. E incluso él mismo está bajo la supervisión de LA BUTACA y de los descendientes del Doctor Milenio.

La vigilancia está justificada porque permite evitar el delito. Con esta información en sus manos, los órganos superiores del poder pueden tratar de disuadir a los ciudadanos de que lleven a cabo sus actos ilegales. La disuasión consistirá en un ocultamiento de la información considerada peligrosa: Anatolio, fun- 
cionario del «Colegio de Relatores de la Ilustre Villa de Madrid [...] encargado de testimoniar su historia presente, sus fastos y duelos, de enaltecer sus portentosas realizaciones y tributar los pertinentes homenajes a sus hijos preclaros» (MF: 70) recibe una advertencia del Delegado para que manipule los hechos y justifique la muerte del Científico Cimero con un tumor cerebral, silenciando su subversivo suicidio (MF: 72); y tras el incendio del Museo ocurrido en la infancia de Matilde, el redactor del periódico escribe una versión destinada a archivarse en la carpeta de «noticias íntegras» y un original, que se publicará, en el que se excluyen «con paréntesis las frases y datos vedados, por orden directorial del periódico» (MF: 225).

Y también se utilizan sanciones: en el caso de Tiburcio, si no devuelve su mono de trabajo limpio al final de la jornada es castigado con una «nimia influencia en el balance que determina la clase de jubilación que [le] concederán» (MF: 14); la sanción impuesta a Tiburcio es disuasoria, pero otras rebeldías se «aplastan, sin trámite judicial», con penas más elevadas, como en el caso de la huida de «madrecita» y Matilde (MF: 60).

Pero la mejor forma de neutralizar a los seres de mayor peligro para la sociedad es convertirlos en inmortales, otorgarles el cargo de cuidar y vigilar a sus conciudadanos. Cuando el suicidio del Científico Cimero contagia a Jerónimo, que gracias a un «desplanificado e ingobernable resquicio de [su] voluntad» consigue llevar a cabo su rebeldía final, los ayudantes del Doctor Submilenio seleccionan para sustituirlo a «los herederos natos de Jerónimo [...]; el temperamento hipercrítico que debemos encauzar» (MF: 286).

Se consiguen así hombres que viven en el engaño sin ser conscientes de ello, que han sido desprovistos de toda fuerza de voluntad. La sociedad está subordinada al Estado, como puntualiza el Científico Cimero (MF: 42), y sus miembros son seres reificados cuyos nombres han sido sustituidos por apellidos oficiales asignados, compuestos por «los números de la fecha de 
nacimiento, la penúltima sílaba del distrito de habitabilidad, el originario, letra final del signo del Zodiaco [...] y la calificación, del 1 al 100», del nivel de «acierto o torpeza genética» de cada individuo, como el código «8-1-1973 — CH-AR-O- 5.45», asignado a Tiburcio (MF: 15). Despersonalizados, se les ha impuesto una matrícula o número de producción en la que se agrupa toda la información que debería ser importante acerca de ellos: su configuración genética, su edad, su procedencia social...

Este sistema de tratamiento cosificador coincide con una serie de regulaciones lingüísticas, que se supone determinan la concepción de los madrileños del mundo y de sus relaciones interpersonales. Algunos ejemplos son la prohibición del tuteo durante las relaciones sexuales entre miembros del Centro Impulsor de Programación Futurológica (MF: 150), la concepción de los usos metafóricos como un «pecado mortal» que hay que evitar (MF: 15) o el afán de concreción excesiva que se consigue por medio del común uso de palabras compuestas como violínsordina (MF: 34), Oficial-Jefe (MF: 35), transmisor-audífono (MF: 43), película-carbón (MF: 225).

Ahora bien, uno de los elementos definitorios de las distopías es la presencia en ellas de al menos un personaje, en la mayoría de los casos el protagonista, que encarna el conflicto entre la sociedad y el individuo. Será necesaria la voz de uno o varios «yoes» que verbalice «la lucha entre el sujeto y el espacio social» (Saldías Rossel, 2015: 162). Ese personaje, excluido por algún motivo de la sociedad, será un antihéroe consciente de su «otredad» dentro de ese mundo (Saldías Rossel, 2015: 162). Hará ver al lector la imperfección de la sociedad ante la que se encuentra, las fallas de las que consta, los horrores sobre los que se asienta.

El «extrañamiento» (Bloch, 1970: 124) de este individuo, que de algún modo se escapa del control alienante del Estado para, desde la distancia, ser capaz de ver sus errores, conlleva también el extrañamiento del lector con respecto a la sociedad distópica. Los motivos del personaje se dan a conocer por medio de la fo- 
calización, habitualmente interna, del narrador: una vez aparece este carácter subversivo, cesa la descripción de una sociedad en cierta medida armónica y pacífica para comenzar la narración de la lucha personal de ese individuo contra el sistema, que con frecuencia se plasma por medio de diálogos del «extrañado» con legisladores o funcionarios en los que se explicitan los aspectos negativos y los elementos favorables de su forma de vida. Se pasa de la generalización de lo que ocurre en el contexto distópico al enfoque particular de lo que le sucede al personaje.

En Mágica Fecha hay grandes grupos sociales conscientes de su estado de alienación. Todos los ancianos, sin ir más lejos, han conocido un mundo distinto, y no pueden evitar compararlo con el presente: por este motivo son percibidos por los más jóvenes como excéntricos e irrisorios. Pertenecen a una etapa pasada que añoran, como Ita, que al pasear por la «acera elástica»

lo consideró un fraude más. Anhelaba que sus zapatos encontrasen el primordial pavimento, duro, rayado, agudizada la difusa nostalgia de la fatiga antigua para ella sensación inteligible. Temía resbalar o hundirse en la materia incógnita, ser víctima de la fabricación voraz, omnisciente. (MF: 18)

Es la sabiduría de la edad, que llevase a los «longevos» a estropear la escalera mecánica y que también personifica Zacarías al tratar de hacer ver a su yerno cómo les «ponen telarañas en los ojos» (MF: 77), con un hablar pueblerino marcado por los hipérbatos, las interjecciones y el léxico asociado a sectores más bajos (son expresiones suyas: «a punto de tortícolis de tanto alzar la gaita», «lo más trillado», «ni de una jota», MF: 77).

Pero no solo los ancianos son conscientes del régimen en el que viven. Otros individuos de mayor peligrosidad para el Estado tienen opiniones semejantes. Tratado como un hombre loco, el Científico Cimero escribe, en el decálogo que se encuentra tras su suicidio, lo siguiente: 
7. Número este cabalístico, augural, afortunado, sugestivo, hipnótico. A él dedico mi heterodoxia, la afirmación, para los Poderes intolerables, de mi libre albedrío. Se trata de un término, de un valor que la colectividad ha perseguido hasta arrasarlo en sus menores brotes, durante siglos. Han obtenido un éxito rotundo, porque todos somos siervos, pero vosotros lo ignoráis. Al tener yo conciencia de ello, recuperé la condición sagrada, falible, estremecedora. (MF: 42)

Cayetano Heriberto es quizás el personaje más fácilmente identificable como un rebelde en esta novela coral, ya que los capítulos quinto, sexto y séptimo consisten en una serie de documentos de los que es autor y narrador en primera persona. En ellos se exponen todos los males sociales que le afectan. Sin embargo, en la conjugación de personajes que acaban protagonizando la acción se percibe el descontento colectivo. La mayoría de los habitantes del bloque vecinal 50 328, Tiburcio, el Delegado, Matilde, el Doctor Submilenio, Jerónimo... tienen algún motivo de queja o de reflexión, porque han conseguido abstraerse de la colectividad. El Doctor Submilenio, en su pesadilla, conoce el peligro de cualquier acto que tenga el poder suficiente como para hacer a los hombres conscientes de su individualidad, pero anuncia que ese acto tendrá que sobrepasar la mera represalia verbal:

- Y te dejaste arrastrar, no fuiste capaz de apostrofarlos, de recurrir al escándalo. Bastaba con el Verbo; que se vieran ante el múltiple espejo que descarna sus rostros, los retrata, para carnet en tamaños de canario, y exhibe, ensartados por un hilo eléctrico, los corazones que la sequía succionó de sangre viva y fluyente.

Aunque los increparas,

a borbotones de amor colérico,

no te oirían.

La palabra perdió

su virtud augural,

cesó de convocar auroras 
y en su plumón

el ocaso no bate

las olas maltrechas. (MF: 203-204)

Y, en efecto, el suicidio del Científico Cimero y las actitudes de una serie de individuos relacionados con él lleva a muchos otros personajes de la obra al extrañamiento y la crítica. Por ejemplo, el decálogo de Cayetano Heriberto, descubierto tras su muerte, hace al Delegado reflexionar sobre el gozo que le produce un acto tan individual como la ejecución del «violín-sordina»:

Y aquella diferencia, privilegio aristocrático respecto a sus vigilados, también aplicable a la generalidad de los habitantes de Madrid, le acercaba, en susurro clandestino, al inventor. Pensó, incidentalmente $[. .$.$] que le agradaría encontrar a un melómano de su$ registro. (MF: 43)

La prostituta Tanagra, tras su relación con Anatolio y el conocimiento del caso del Científico Cimero, se plantea si realmente quiere continuar con su trabajo para las Compañías Recreativas Discrecionales:

Y me preguntaré, al término de cada encuentro, en su probable disgusto de regusto raras veces, imbuida por las interrogaciones de Anatolio, si en verdad y en integridad puedo considerarme un ser vivo. ¿O yo y los demás, todos los que he conocido, vivimos sin ser o nos hacen ser sin vivir? (MF: 266b)

Y, también como aspecto distópico fundamental, tenemos que hablar de la implicación del carácter mimético (imitativo de la realidad) ficcional (no completamente fiel a esa realidad) de los mundos representados en este tipo de obras. Saldías Rossel define la relación entre los hechos narrados en la obra distópica recurriendo al término que toma de Andreu Domingo, «doble marco temporal»: 
[La] doble temporalidad intra y extraliteraria genera un efecto paradójico con la lógica de la narración, pues plantea implícitamente que lo que está sucediendo en el texto es, por definición, completamente diferente a lo que ha sucedido en la realidad. Sin embargo, al mismo tiempo que se niega la factibilidad de los eventos narrativos, se plantean como evento [sic] verosímiles, lo que a su vez permite la formación de una eventual crítica de la sociedad a partir de los excesos retratados en este tiempo alternativo. (2015: 157)

Podemos tomar de Bloch (1970: 125) el término especularidad, que él aplica a obras utópicas, al teatro del absurdo o incluso a Hamlet, para explicar este fenómeno. El modelo social distópico reproduce cuestiones del mundo presente en un locus exótico: de este modo el lector, al leer la obra identifica en ese mundo distinto del suyo, ficcional, situaciones y hechos que están en relación con el presente que él está viviendo. Al leer sobre ese otro mundo y reflexionar sobre los aspectos que en la obra distópica se ponen en cuestión, está reflexionando también sobre su contemporaneidad. Igual que el personaje enfrentado al sistema distópico dentro del texto que tiene entre las manos, el lector sale de su irreflexiva alienación cotidiana por medio del extrañamiento (Bloch, 1970: 124).

En Mágica fecha, por medio de los pasajes introspectivos y de los diálogos teatrales (género textual en que están escritos, al menos parcialmente, los capítulos «Antepenúltima»y «Penúltima»), y gracias al abundante uso de la primera persona reflexiva, en alternancia con la narración en tercera persona, el lector alcanza a conocer las insatisfacciones de todos los personajes, e incluso puede entender cómo se despierta la conciencia de los mismos. Ya desde el principio de la obra el lector va tomando él también conciencia de manera que no puede eludir percatarse de las cuestiones que entran a debate en la novela. Temas como el de la funcionalidad y la efectividad del hombre, el desajuste generacional, la eutanasia, el cinismo o incluso la maldad y la existencia inmisericorde pasan por la cabeza de quien va desgranando la redacción compleja, confusa, de ese mundo futurista en el que se refleja el nuestro. 


\section{De la ficción a la realidad: nueva visita a Mágica fecha}

Veintiséis años después de la publicación de Un mundo feliz Aldous Huxley repasaba la evolución de las cuestiones que él había abordado en su ficción en una serie de ensayos acerca de la realidad y el posible futuro de la sociedad occidental, Nueva visita a un mundo feliz. El autor inglés explicitaba de este modo las preocupaciones que le habían llevado a escribir su distopía, su crítica especular, y desvelaba la capacidad de una ficción futurista para suscitar reflexiones sobre distintos momentos históricos.

Como hemos tratado de exponer lo largo de este artículo, hay una serie de convenciones genéricas, comunes en todas las distopías, cuyo tratamiento no implica necesariamente una llamada de atención al lector sobre un hecho concreto que esté sucediendo en su entorno inmediato. Pero es posible, más allá de estas convenciones, extraer del texto los aspectos que más preocupan al autor y que se convierten en las cuestiones principales de la obra dándole su carácter peculiar.

En la novela que estamos comentando uno de esos temas principales es el cambio generacional. La falta de comprensión entre jóvenes y ancianos, la clarividencia de los mayores, su conocimiento del pasado, etcétera, son cuestiones capitales para el autor. Personajes como Ita, Jerónimo, Zacarías, Calixto y Lucrecia son capaces de ver los fallos, los «engaños» y las debilidades que acarrea el desarrollo productivo. Su nexo con el pasado les lleva a una ineludible comparación del estado de cosas anterior con el actual, y sufren la inadaptación de quien vive en el recuerdo.

La angustia existencial de estos individuos, desplazados, «obsoletos», puede identificarse desde luego con la de un autor, entrado ya en la madurez, que a su regreso a España se encuentra con un olvido radical de lo que era el país antes de -y durante- la dictadura franquista. Ya desde la novela Cita de fantasmas (1982) ${ }^{4}$,

4 O incluso desde antes, como indica la aparición del tema en su epistolario de 1968, Cartas son cartas: «Has puesto el dedo en la llaga, en mi llaga, al abordar, con 
Manuel Andújar focalizaría su preocupación por España en los «cachorros», la generación más joven, y en la «bifucación vital y espiritual de nuestra cultura» (1987: 21b). El miedo al «olvido impunista» y el «dilema moral de si la averiguación de los traumas ocasionados por la guerra civil debe o no convertirse en materia de asimilación comunal» (1987: 22a), presentes en La voz y la sangre (1984), encuentran su camino en Mágica fecha, donde la memoria escrita se manipula, la Historia se archiva y olvida, y el recuerdo se considera un pasatiempo improductivo e improcedente: es «una "puerilidad" secundar la nostalgia de los "antiguos" por lamentar la pérdida de algo que no [se] conoció» (Vegazo Palacios, 2002: 354).

Por otra parte se puede apreciar una profunda aversión a la eficacia, valor - también racionalista- central de la existencia individual. Este tema se torna en cuestión principal de la obra a través de una concepción negativa de la meritocracia, de la vigilancia de la muerte y de la eugenesia - las primeras más presentes en el mundo real de la España de finales del siglo xx que la otra-; pero también del uso del lenguaje como herramienta eficaz. Andújar reclama como valor ético la libertad, la antieficacia, el deleite, la individualidad, el pensamiento abstracto, el lenguaje «no reprimido ni represivo» (Andújar apud PiñaRosales, 1988: 113). A la par, se perciben también como temas primordiales la falta de «verdadera solidaridad» (MF: 42) humana y la soledad del hombre en su entorno social, producto de la imposibilidad comunicativa en un mundo burocratizado hasta los límites, preocupado hasta el extremo por la producción y la ganancia económica. En ese horizonte desolador y carente de valores en el que no queda conciencia ninguna de la integración orgánica, necesaria para la vida en comunidad, el arte se yergue como esperanza: Golondrina pervive en su arte de trapecista, el Delegado alberga la esperanza de encontrar a otros individuos apasionados por la música,

una claridad para mí valiosísima, el tema de la guerra civil y cómo la considera la generación joven. $Y$ tus experiencias en ese terreno» (62). 
como él; el bloque comunal se une para ensayar un himno, esperanzado, y Matilde y Zacarías se juntan en un baile que aglutina generaciones y sentires distintos. La imaginación, tantas veces rechazada por los personajes de la novela, parece sobreponerse al racionalismo científico que considera los «emociones solo merecedoras del simple examen químico» (MF: 183).

En el ámbito estilístico, hay en Mágica fecha una crítica a la literatura de consumo rápido, al lenguaje facilitado y a la vacuidad del «bestsellerismo» (Andújar apud Piña-Rosales, 1988: 112). La escritura casi ocultista de esta obra, la mezcolanza de voces, la complejidad estructural y la difícil comprensión de la trama pueden interpretarse como un reto al público, una forma de impedir la lectura superficial de la novela y de exigir al lector la búsqueda de un sentido, de unas implicaciones ideológicas, en el texto. Es la llamada a un público activo, crítico, cuyo potencial reflexivo debería sobrepasar los límites de la ficción para extenderse a la vida diaria, al devenir cotidiano de la existencia, en un continuo cuestionamiento de lo preestablecido, en una negación del «conformismo corruptor» (Andújar, 1968: 106). Además, claro está, de un afán de innovación del género novelístico, que a veces puede entenderse como intento de trascender la historia para abarcar las «intrahistorias» (usando el término unamuniano) de sus personajes: sus percepciones, sus visiones del mundo, la simultaneidad de sus vivencias —en los capítulos «Antepenúltima» $\mathrm{y}$ "Anteúltima», en que la acción se distribuye en los ejes X, Y y Z, en dos columnas temporalmente parejas-; y, en definitiva, sus individualidades. Todo ello revestido de una cierta ironía, un tono humorístico que recalca el absurdo de la casi totalitarista sociedad futura, restándole realismo (en el sentido tradicional del término) y elevándola al nivel simbólico del esperpento. La sociedad del Madrid de 1999 se refleja como un enorme guiñol, una farsa de la que todos participan, de la que no consiguen escapar. 
Coincide con estas ideas, a grandes rasgos, la breve descripción de Mágica fecha propuesta por Santos Villanueva:

El predominio de un materialismo imparable, la pérdida de la memoria histórica, la relativización de los principios, la ética del triunfo social o económico... le producían un intenso malestar que a duras penas compensaba con una fe venida de antiguas creencias humanistas que le servían de consuelo y aun de esperanza. [...] No podía aceptar que tantas ideas hermosas fueran arrasadas por una sociedad cada día más maleada, ni que se perdiera para siempre un horizonte de utopía. Mientras, mantenía una actitud bastante solitaria de denuncia de una situación decadente, que le parecía muy alarmante en el terreno de la cultura. [...] La culpa la compartían los creadores y los destinatarios: aquéllos por convertir su papel en una farsa burocrática; éstos, por desentenderse de lo espiritual una vez solventadas muchas aspiraciones materiales. La conclusión era ácida: el sestear de las letras, artes y ciencias se debe a que han periclitado para siempre los sistemas morales «todavía en circulación externa». De todo ello habla, a su manera parabólica, la mencionada Mágica fecha. (1995: xxv)

Podemos entender, por tanto, que cuando Manuel Andújar se decidió al fin a publicar Mágica fecha, en 1989, lo hizo con la conciencia de estar cerrando el ciclo Lares y penares. En una progresión temporal que comenzaba narrando el preludio de la Guerra Civil para relatar a continuación los sucesos que giraron, dentro y fuera de la Península, en torno a este acontecimiento histórico, parece razonable entender la novela futurista como una advertencia de que no todos los males de la sociedad española finalizaron con la Dictadura. Igual que el resto de novelas de la serie narrativa, la obra de 1989 está movida por la necesidad de explicar el presente (Alarcón Sierra, 2015: 146). Cerrando el siglo que abarca el ciclo completo, 1999 se convierte en la localización de una historia cuyos miembros se ven atacados por peligros desapercibidos para el hombre moderno en su día a día.

Con un tono irónico, desencantado y pesimista, Andújar ceja en su intento de explicar las causas y los antecedentes de su ac- 
tualidad inmediata para prevenir sobre el futuro. La imagen derrotista que se dibuja en su novela no es ya una justificación, no se reduce a mostrar el devenir de la Historia, sino que se convierte en una advertencia para el lector. Porque al igual que la trilogía Vísperas había explorado el clima social previo a la Guerra Civil, el presente del escritor andaluz estaba vaticinando el mundo distópico de Mágica fecha, un mundo todavía en potencia, aún evitable.

En una profunda indagación antropológica, Andújar reivindica aquellos valores que, siente, se han olvidado como consecuencia de la globalización y del aperturismo económico postindustrial, novedosos en la España de los últimos años de la Dictadura. Reclama sobre todo el pensamiento crítico, la actitud reflexiva en un contexto en el que el tiempo se rinde a la imperante necesidad de producción y efectividad. Todo ello lo consigue mediante la consciente deformación de personajes y situaciones, trascendiendo las convenciones estilísticas de la novela y rebelándose contra las características restrictivas del género narrativo y del lenguaje, elevando su crítica a la dimensión técnica de la narración.

\section{Referencias bibliográficas}

Abellán, José Luis (1994) «Manuel Andújar, literatura y conciencia», en Cuadernos Hispanoamericanos, 529/530, 281-294.

Aguilera Malta, Demetrio (1962) «El teatro: un nuevo aspecto de Manuel Andújar», en Manuel Andújar, El primer juicio final. Los aniversarios. El sueño robado, México D. F., ed. de Andrea, 7-11.

Alarcón Sierra, Rafael (2015), «Lares y penares, el ciclo narrativo de Manuel Andújar», en Boletín de Estudios Giennenses, n.ํㅜ 211, 143-160.

Andújar, Manuel (1968), Cartas son cartas, México, Finisterre.

- (1987) «Manuel Andújar: Una versión fragmentaria de obra y vida», en Anthropos, 72, 15-22. 
- (1989) Mágica fecha, Barcelona, Anthropos.

- (2004) Mágica fecha, Barcelona, SIC idea y creación editorial.

Basanta, Ángel (15 de abril de 1990) «Mágica fecha», en $A B C$ de Madrid, n.o 830, 62.

Beneyto, Antonio (1975) «El testimonio perenne de Manuel Andújar», en Censura y política en los escritores españoles, Barcelona, Euros, 83-89.

Blanco Hervás, Rocío, Tellado Campaña, Vanessa y Torres Escobar, Francisco (2013) Manuel Andújar desde Jaén. Documentos para un centenario (1913-2013), Jaén, Instituto de Estudios Giennenses.

BLOCH, Ernst (1970), «"Entfremdung, Verfremdung": Alienation, Estrangement», Anne Halley y Darko Suvin (trads.), en The Drama Review, vol. 15, n. ${ }^{\circ}$ 1, 120-125.

Calatrava, Juan (2010) «El espacio utópico, una conversación con Raymond Trousson», en Minerva: Revista del Círculo de Bellas Artes, n.. 14, 40-44. [En línea, consultado el 25/04/2017: <www. circulobellasartes.com/revistaminerva/articulo.php?id=404>].

Claeys, Gregory (2010) «The origins of dystopia: Wells, Huxley and Orwell», en Gregory Claeys (ed.), The Cambridge Companion to Utopian Literature, Cambridge, Cambridge University Press, 107-134.

Conte, Rafael (1980) «Vísperas, el realismo simbólico de Manuel Andújar», en Domingo Ynduráin (coord.), Historia y crítica de la literatura española. Época contemporánea, 1939-1975, Barcelona, Crítica, 547-555.

— (29 de abril de 1990), «Entre el símbolo y la ficción: Mágica fecha», en el suplemento de libros de El País de Madrid. [apud Medina Ávila, 2014: 693]. 
Cuddon, J. A. (1999) The Penguin Dictionary of Literary Terms and Literary Theory, London, Penguin Books.

Galán Rodríguez, Carmen (2007) «Logomaquias y logofilias: distopías lingüísticas en la ficción literaria», en Anuario de Estudios Filológicos, XXX, 115-129.

GALDón Rodríguez, Ángel (2011) «Aparición y desarrollo del género distópico en la literatura inglesa. Análisis de las principales antiutopías», en Prometeica, 4, 22-43.

GonzÁlez de GAmbier, Emma (2002), Diccionario de terminología literaria, Madrid, Síntesis.

Gray, Martin (2004) A Dictionary of Literary Terms, Essex / Beirut, Pearson Education Limited / York Press.

Hervás Fernández, Gloria (2011) «Manuel Andújar, un escritor del exilio», en Revista de Filología Románica, anejo VII, Escrituras del exilio, 163-170.

Huxley, Aldous (1985) Nueva visita a un mundo feliz, Barcelona, Seix Barral.

ÍmAz, Eugenio (1941) «Topía y utopía», en Eugenio Ímaz (ed.), Utopías del Renacimiento, México, Fondo de Cultura Económica.

Martínez Aguilar, Miguel (1989) «La narrativa de Manuel Andújar», en Boletín del Instituto de Estudios Giennenses, 139, 101-128.

Mateo Díez, Luis (1998), «Introducción», en Manuel Andújar, Cuentos completos, Madrid, Alianza Editorial.

Medina Ávila, Blas (2014) Manuel Andújar, su correspondencia, fe de vida y de obra, tesis inédita presentada en la UNED. [En línea, consultado el 20/3/2017: <hdl.handle. net/10803/403324>].

Piña-Rosales, Gerardo (1988) Narrativa breve de Manuel Andújar, Valencia, Albatros Hispanófila. 
Pulido Tirado, Genara (2005) «Manuel Andújar: compromiso político y literario», en Compromiso histórico y teoría cultural en Manuel Andújar, Córdoba, FUDEPA. [En línea, consultado el 13/2/2017: <www.fudepa.org/FudepaWEB/ Publicaciones/ManuelAndujar/ManuelAndujar.aspx>].

Rodríguez PADrón, Jorge (1990), «La narrativa de Manuel Andújar», en Cuadernos Hispanoamericanos, 475, 137-140.

Ruiz-Copete, Juan de Dios (2001) «Manuel Andújar», en Narradores andaluces de posguerra: historia de una década (1939-1949), Sevilla, Editorial Universidad de Sevilla, 35-74.

Saldías Rossel, Gabriel Alejandro (2015) En el peor lugar posible: Teoría de lo distópico y su presencia en la narrativa tardofranquista española (1965-1975), tesis inédita, Universidad Autónoma de Barcelona.

Sanz Villanueva, Santos (1995) «Introducción» en Manuel Andújar, Lares y penares, México, Fondo de Cultura Económica.

Shipley, Joseph T. (1962) Diccionario de la literatura mundial. Crítica - Formas - Técnica, Rafael Vázquez Zamora (trad.), Barcelona, Ediciones Destino.

Soldevilla-Durante, Ignacio (1989) «La evolución constante del novelista Manuel Andújar», en España Contemporánea, t. II, no3, 25-36.

Stringer, Jenny (ed.) (1996) The Oxford Companion to Twentieth Century Literature in English, Oxford, Oxford University Press.

Suvin, Darko (1990) «Locus, Horizon, and Orientation: The Concept of Possible Worlds as a Key to Utopian Studies», Utopian Studies, vol. I, no 2, 69-83.

Trousson, Raymond (1995) Historia de la literatura utópica. Viajes a países inexistentes, Carlos Manzano (trad.), Barcelona, Ediciones Península. 
VAn Gorp, Hendrik et al. (2001) Dictionnaire des termes littéraires, Paris, Editions Champion.

Vegazo Palacios, Vicente (2002) «Manuel Andújar: Cita de fantasmas o la vindicación del pasado», en Cultura, historia y literatura en el exilio español de 1939: actas del Congreso internacional «Sesenta años después» (Andújar, Jaén, 1999), Jaén, Universidad de Jaén, 349-362.

Claudia Sofía Benito Temprano Universidad AutónOMa DE MADRID claudiaben.35@gmail.com 